\title{
THE RESENTFUL AND THE INDIGNANT
}

\author{
DAVID BOTTING ${ }^{1}$ \\ (Universidade Nova de Lisboa, Portugal)
}

\begin{abstract}
In "Freedom and Resentment" P.F. Strawson distinguishes between the participant reactive attitudes like resentment and the moral reactive attitudes like indignation described by Strawson as their "vicarious analogues," where we are not the injured party and it is not our own personal relationships at stake. Through naturalistic description of the participant reactive attitudes a set of conditions for moral responsibility can be discovered that, moreover, are held to be immune to any external review or to require external justification. Except for pathological cases Strawson deems to amount to solipsism, these participant attitudes and their vicarious analogues are deemed to go together and the same arguments to apply equally to each: resentment and indignation are supposed to have the same conditions for being appropriately held or witheld. I find it to be not obvious that these conditions must be the same, but even if they are, the case for immunity that Strawson presents initially for the participant reactive attitudes does not transfer as unproblematically as he seems to assume to the moral reactive attitudes. The aim of this paper is not to analyse Strawson's arguments, but more simply to identify a number of ways in which we may be resentful without being (or being prone to be in the relevantly similar circumstance) indignant, and indignant without being resentful.
\end{abstract}

Keywords: Resentment. Indignation. Reactive attitudes. P.F. Strawson.

\section{Introduction}

The aim of this paper is to show that one may be rightly resentful even in cases where one would not, if one were not the injured party, be rightly indignant, or at least it would not be wrong not to be indignant. Though more rare, there may also be cases where one would be not rightly resentful (or at least it would not be wrong not to be resentful), but rightly have one of the so-called cooler reactive attitudes, whether this is a participant attitude or a moral attitude like indignation.

One of the things I will be relying on is the idea that in the participant and generally 'hotter' reactive attitudes the appeal to reasons tends to be after the fact: we do not deliberate on whether to resent and then decide to resent, we resent first and then notice upon reflection that our resentment seems to be sensitive to certain kinds of reasons, without necessarily saying that we consciously reason. In the non-participant and cooler attitudes, in contrast, there is more of a possibility of a rational deliberation, which is to say that the appeal to reasons may sometimes be before the fact. To put it another way, when we resent, we resent according to certain rules regulating our network of attitudes, but when we are indignant we are more likely to follow them. Thus, a more reflective attitude towards the rules themselves 
may be taken when we are not the participant, especially if the individual case is one where we have conflicting intuitions about what the rules should be or whether they are being correctly applied.

In the first section I will describe Strawson's view on how various classes of reactive attitudes go together. There are three types of reactive attitude: the participant reactive attitudes (such as resentment), the moral reactive attitudes (such as indignation), and the selfreactive attitudes (such as guilt).

In the second section I will show that indignation may be sensitive to a wider range of reasons than seem to be available in the case of resentment, including metaphysical beliefs. Hence, the argument that reactive attitudes are not sensitive to metaphysical beliefs does not extend unproblematically from resentment to indignation. The problem is that Strawson's claim that the network of attitudes need not be justified because essentially involved in interpersonal relationships to which we have a kind of natural commitment does not seem to apply equally when we are not a participant in those interpersonal relationships.

This is not just an explanatory gap in Strawson's account of the moral reactive attitudes, as it is for Bennett, but a direct challenge to Strawson's naturalistic strategy that does not seem to be solved by Bennett's suggestion that we see moral reactive attitudes as aiming at relationships; even if we are not required to justify (our commitment to) relationships we are in, it does not follow that we are not required to justify (our commitment to) relationships that we only aim at. ${ }^{2}$ So even if we accept Strawson's point that resentment and indignation tend to go together, it does not necessarily seem to follow that they are both equally immune to the question of whether they are justified, and if we are to justify them with reasons, I see no reason to suppose that these reasons cannot go beyond those appealed to in having the attitude itself. So, we may withhold or withdraw our feelings of indignation, although we are still resentful. We may not be sure that our indignation is appropriate, and arguably this may go even as far as feeling that indignation is inappropriate, under the circumstances.

In the third section I will consider the fact that our resentment may have a so-called seamy side and may not in fact be sensitive to reasons as such, but are rather explained as the outcome of subconscious processes and the like. I do not think this is so much of a problem for resentment but may be for indignation. This is because, as resentment's more reflective cousin, it is more consciously concerned with having the right attitude in every single instance, whereas resentment itself, even when it gets its facts wrong, is not for that reason unjustified. Even when the resenter's appeal to reasons is an after the fact rationalization, it is 
enough that the resenter takes those reasons to be explanatory that identifies those reasons as regulating the participant reactive attitudes as a class and also the network of attitudes of the resenter himself. The seamy side does not prevent the natural facts about our attitudes from revealing what we take to be our conception of moral responsibility. Again, we would not be obliged to withdraw the resentment (even if, is a matter of fact, it was motivated by the seamy side) but could be obliged, or believe ourselves to be obliged, to withdraw the indignation in such a case.

In the fourth section I will consider cases of so-called moral dumbfounding. These are cases where our intuitions may conflict and bring in rational deliberation to try to resolve the conflict. The result of such deliberation might be to be indignant but not resentful. But I also think that one may still trust the intuition and resent, but suspend the indignation because we are not really sure whether it is rationally justified or not. Hence, this is a case where each can be had without the other.

In the conclusion I will consider what the consequences are for moral responsibility itself, if we take the view that our holding someone morally responsible amounts (in some way) to their being morally responsible. What class of reactive attitudes are expressed when we hold someone morally responsible? Before we never had to answer this question, because it was assumed that we would get the same result whichever class we chose. It is not the purpose of this paper, however, to give an answer to this question.

\section{The inescapability of resentment and indignation}

One of the main planks in Strawson's argument in "Freedom and Resentment" is the claim that our reactive attitudes do not need any kind of external justification; they cannot come up for review. This has been summed up in the phrase that the reactive attitudes are inescapable. In my view this phrase is not an entirely appropriate one, and it is not Strawson's. The word "inescapability" makes it seem like, once we have a reactive attitude nothing can dislodge it, and this is not true, for Strawson describes reasons for which we already, as a matter of fact, withdraw or mollify our reactive attitudes. There are also those who, often for religious reasons, foreswear any retributive emotion. It is not an impossibility that there be entire cultures that do this. This word "inescapability" leads us astray into thinking that it is just psychologically impossible, or at least extremely difficult, to give up these attitudes. Although I agree that it is the network of our psychological states that is in 
question, I do not think this is the right way to interpret Strawson's argument.

I will here only describe my alternative interpretation briefly. Strawson talks about certain kind of commitments we have as human beings. We start off in certain interpersonal relationships, and these are not something that we rationally deliberate about having or take to require justification. We may sometimes deliberate about keeping the interpersonal relationship, and sometimes cut off the interpersonal relationship, but this is usually because, in the context of the relationship, the other party has done something which makes this appropriate.

These interpersonal relationships - or at least the kind of reciprocal relationships that we take to be most valuable to us - are such that they require reactive attitudes. A relationship like love, for example, will be such that certain reactive attitudes will be appropriate in certain situations. So there is a network of attitudes that are involved in the relationship of love, including, in some situations, its replacement by hate or simply indifference; it is not only reactive attitudes that are relevant, but any attitude at all that is an appropriate modification of the reactive attitude, where this modification itself may or may not be reactive. It is not merely a matter of psychology but a conceptual matter of love being what it is that we would not be in love if we did not respond in these appropriate ways. Although one slip would not derail the entire relationship, it is certainly not possible genuinely to be in this relationship and not have any of the attitudes or emotions involved in it. The lover who was entirely indifferent to being loved in return, for example, could not seriously be thought to be in a relationship of love with the object of his affections. Today we would be more likely to describe such a person as a stalker than a lover.

It is a conceptual point, then, that a certain network of attitudes is involved in certain reciprocal relationships. We have a commitment to reciprocal relationships that we are actually in, and would not abandon them even if we believed them to be unjustified, any more than we would cease to reason inductively even if we thought that induction was unjustified. This does not follow for relationships that we are not in. If we are faced with a choice between entering a relationship or not then we may deliberate about whether we should do so, and may choose not to do so if we believe the attitudes it involves would be unjustified. There is no commitment for these relationships. But normally this is not the situation we are actually faced with; the choice is not simply between having and not having a particular relationship, but between keeping a relationship that in fact we have, and giving up that relationship. Because there is a commitment to the relationship, there is a commitment to the network of attitudes. 
In defending his claim that our reactive attitudes do not need any kind of external justification, Strawson makes heavy use of interpersonal relationships, and I would claim that it is because we do not need external justification for those interpersonal relationships we are in that we do not need external justification for the reactive attitudes involved in those particular relationships. But in the second half of his paper where he discusses non-participant reactive attitudes, talk of interpersonal relationships vanishes completely. This seems sensible enough, since non-participants are not in the interpersonal relationship.

Instead of linking non-participant reactive attitudes to interpersonal relationships Strawson links them to the participant reactive attitudes. Strawson argues:

\begin{abstract}
The generalized or vicarious analogues of the personal reactive attitudes rest on, and reflect, exactly the same expectation or demand in a generalized form; they rest on, or reflect, that is, the demand for the manifestation of a reasonable degree of goodwill or regard, on the part of others, not simply towards oneself, but towards all those on whose behalf moral indignation may be felt, i.e., as we now think, towards all men. The generalized and non-generalized forms of demand, and the vicarious and personal reactive attitudes which rest upon, and reflect, them are connected not merely logically. They are connected humanly; and not merely with each other. They are connected also with ... self-reactive attitudes associated with demands on oneself for others....

All these three types of attitude are humanly connected. One who manifested the personal reactive attitudes in a high degree but showed no inclination at all to their vicarious analogues would appear ... as a kind of moral solipsist. Let him be supposed fully to acknowledge the claims to regard that others had on him, to be susceptible of the whole range of self-reactive attitudes. He would then see himself as unique both as one (the one) who had a general claim on human regard and as one (the one) on whom human beings in general had such a claim. This would be a kind of moral solipsism. But it is barely more than a conceptual possibility; if it is that. In general, though within varying limits, we demand of others for others, as well as of ourselves for others, something of the regard which we demand of others for ourselves. Can we imagine, besides that of the moral solipsist, any other case of one or two of these three types of attitude being fully developed, but quite unaccompanied by any trace, however slight, of the remaining two or one? If we can, then we imagine something far below or far above the level of our common humanity - a moral idiot or a saint. For all these types of attitude alike have common roots in our human nature and our membership of human communities. ${ }^{3}$
\end{abstract}

Here Strawson seems to be saying that it is more or less a practical impossibility for someone to be such that they entertained one type of reactive attitude but withheld from another type, for this would be to make an unprincipled exception of oneself from others; the reactive attitudes come as a package deal for all but the most pathological cases. On this basis Strawson claims that the three kinds of attitudes are "humanly connected." Also, it is the same conditions that regulate indignation as regulate resentment. ${ }^{4}$

Helm expands on this passage. The attitudes are all "logically connected" in having the same formal object, namely that they are "all negative evaluations of someone for 
violating an expectation or demand of goodwill towards someone else." They are "humanly connected" by virtue of

\begin{abstract}
connections that hold between feeling one reactive attitude and feeling others. There would be something odd about feeling resentment towards someone who did something to you and yet to fail to feel indignation towards her were she to do it to someone else or even to fail to feel guilty were you to do that same thing to another person.... The oddity, as Strawson indicates, has its source in the kind of demands or expectations we have of people's treatment of other people quite generally, but it is an oddity that points to the way these demands or expectations can be unified through the sort of human connection among reactive attitudes he is after. Thus it begins to look as though the human connection, by unifying such expectations, is more fundamental to understanding the reactive attitudes than the logical connection. ${ }^{6}$
\end{abstract}

\title{
The commitment to indignation
}

Consider the case of someone treading on my toe: there is a human commitment to resentment towards the toe-treader by the toe-treadee. Is indignation the prescribed appropriate response for an onlooker? Could it be the case that the onlooker is not indignant (and is not wrong not to be indignant) though he would be resentful were he the injured party? And this despite not being any kind of solipsist?

Strawson's appeal to the human commitment to participant reactive attitudes does not rule this out. I agree with Strawson that this would be an unusual situation, and with Helm that one would have a more unified set of attitudes if one were disposed to have indignation in the same cases, the identity of the injured party apart, as where one would have resentment. I even would claim that when one feels resentment one does so because the expectation that has been violated is a special case of a general demand incumbent on the moral community as a whole, and that when expressed as blame, that blame gets its force and much of its authority from the fact that the blamer represents the moral community as a whole. It seems to be part of the phenomenology of such attitudes that they are felt to be agent-neutral in this way and that the scope of blame implicates all relevantly similar acts and agents. It is the moral community that the responsible agent is ultimately responsible to.

However, even if these things are so it is not obvious that it establishes that moral reactive attitudes do not require, or are protected from, justification; this is because it is not obvious that indignation is as much given to us as a fact of human society as resentment is or is as closely connected to any relationship we are humanly committed to; on the contrary, it seems quite plausible to suppose that how we regulate our moral attitudes and the moral 
demands we place on each other evolve with the society itself. Not only can they come up for review, the evidence seems to be that they are reviewed and sometimes changed. This is because, not having a human commitment to them, we can take a more reflective attitude towards them and towards the rules we follow.

The kind of empirical and contingent link Strawson makes here does not seem strong enough for the human commitment to transfer unproblematically from resentment to indignation - it seems too much like a psychological claim. The mere possibility of the pathological case, and the fact that even in non-pathological cases the attitudes may be held in different degrees, seems to open up the possibility that some attitudes and some degrees of attitude may be more justified than others. An agent that felt resentment but would not feel indignation if another were the injured party may be odd, but it is not obvious that he is irrational, or a solipsist. Unlike before, there is not necessarily a pre-standing commitment to indignation and we can be in the position of being neutral between feeling indignation and not feeling it. We are more liable to rational deliberation, and while conformity with resentment may be a factor, it need not be definitive, for then there would be no point in rational deliberation at all.

\section{The seamy side of reactive attitudes}

Can our commitment to resentment be challenged by the fact that it has a seamy side? We may be mistaken about what our reactive attitudes, especially our retributive attitudes, depend on. It may not be, as Strawson suggests from considering the natural facts of our moral practices, that the agent is resented because he manifested a morally bad quality of will or is not resented because of being a moral idiot, but because of facts about ourselves, working in our subconscious, that explains why we resent or do not resent when we do. There is a psychological pre-disposition towards retribution that would bias all our results. If this were pervasive, it would suggest that naturalistic description of our moral practices of the rationalizing kind that gives us reasons, is no guide at all to why we actually have the attitudes that we do.

Strawson says this:

$[\mathrm{P}]$ sychological studies have made us rightly distrustful of many particular manifestations of the attitudes I have spoken of. They are a prime realm of selfdeception, of the ambiguous and the shady, of guilt-transference, unconscious sadism and the rest. But it is an exaggerated horror, itself suspect, which would make us unable to acknowledge the facts because of the seamy side of the facts. . . ? 
Strawson's point is not exactly clear here. In the end he seems to appeal to a practical argument; it does not seems practically possible to give up all reactive attitudes just because some of them do not depend on what we thought they depended on. ${ }^{8}$ Possibly, Strawson assumes that attitudes that are explained this way are in a minority and consequently do not really challenge our commitment to them.

I propose a slightly different response. Even if what we give as a reasons-explanation of our attitude is not the real explanation, the fact that we take it to be so reveals something both about our moral practices and about our conception of moral responsibility. In reconstructing the conception of moral responsibility from naturalistic description it is the rationalizations, after all, that are relevant, and not the causal/mechanistic explanation given by our unconscious drives - the latter is the wrong kind of reason. Plausibly, there are many cases where the reasons-explanation is the real explanation, for otherwise we would not take our rationalizing explanations to be explanatory at all. Consequently, that in some particular cases another, perhaps better explanation is available does not mean that this is no guide to the reasons according to which we regulate our reactive attitudes.

Suppose now that we have a situation where our resentment is a case of guilttransference and the agent, in fact, is not morally responsible. So, the resentment is inappropriate, there being no moral demand that the agent has violated. Does this mean that we are not committed to this resentment? I don't think so. Saying that our attitudes do not need to be justified is not to say that they cannot be in factual error. If we explained to the resenter the reason for his resentment, his response would simply be that he has misapplied his conception, made a performance error in acting according to the rule. This does not challenge the framework of our reactive attitudes, or our human commitment to them.

So, the fact of a seamy side itself does not bring into doubt all our retributive attitudes. Strawson, I think, in this respect gives the argument too much credit. But once again, it is not clear whether the argument cannot gain some traction in the realm of the moral reactive attitudes. This is because we may feel that the rules we are following are unsafe.

One can imagine it being considered unsafe in various ways. One way is that we lose confidence in the content of the rule itself: the seamy side may bias the sample from which we draw generalizations, and we may consider that we simply do not have an appropriate data set to start from. Another way is that we may be confident in the content of the rule, but lack confidence in our ability to follow it correctly; this is probably more likely when we rationally deliberate, for we may be aware that the high affect of the retributive emotions may be biasing 
our psychological processes, including that of reasoning. A third way is that one might imagine entering a meta-level in which we reason about the reasons for our attitudes, and here the seamy side might again make us reluctant to be indignant while these issues are unsettled. In each case, the doubtful aetiology of the attitudes and our acknowledging the possibility this raises of factual error, may make us prefer to suspend our indignation rather than express it, and such a possibility may even make indignation unjustified, whereas resentment, not needing any justification, can be the appropriate attitude for a subject to have (from their own point of view) despite this possibility.

\section{Morally dumbfounding cases}

Consider a case where the retributive feeling is particularly intense, and yet at the same time you sympathize with the wrong-doer because of a particularly egregious upbringing. We feel conflicted. Waller explains this conflict as being between our fairness intuition and the retributive impulse, resulting in "moral dumbfounding." In such circumstances we are more likely to appeal to rational deliberation, and this, I have said, is to deliberate about indignation.

When the crime is so horrible and our retributive reactive attitudes so intense I think that it is quite possible that we put greater faith in our attitudes, and if this conflicts with the rules, then so much the worse for the rules. The rules must either be adapted to the new case, or we may be more prepared to think that we have committed a performance error rather than modify the attitude or the rule, or we may simply ignore the rule. Worrying about the rules in such a situation may seem curiously out of place here, as evidencing a misplaced priority on a certain kind of fastidiousness rather than reacting properly to the violation. However, indignation plausibly does depend on following rules, and rationally deliberating about indignation even more so. So, here also may be a case where we keep the resentment but suspend the indignation.

Interestingly, Waller suggests that the result of such deliberation might be to adopt the fairness intuition and to resist the retributive impulse. ${ }^{10}$ That is to say, we may suspend resentment, but indignation still seems open to us. Unlike in the previous cases where one could be resentful without necessarily being indignant, in the case of the morally dumbfounded there seems to be a possibility that one could be indignant without being resentful. 


\section{Conclusion}

In this paper three ways have been described in which one may appropriately be resentful without being indignant. There are probably more. I have taken for granted Strawson's arguments that the network of reactive attitudes does not require justification with respect to the participant reactive attitudes. Thus (with one possible exception) it is the moral reactive attitudes that are suspended. If Strawson's arguments don't work there may be more cases where we are indignant without being resentful. In fact, even according to Strawson's own account, there are cases where we may choose not to be resentful, and it is not entirely obvious that we could not choose this in some particular case and for the same kind of reasons that I have argued may bring us to suspend our indignation. In such cases we may bring our attitudes of resentment and indignation back in line, though it is not that suspension of resentment is positively required from fear of being unjustified; this is not always the case when suspending a moral reactive attitude, which I think in many cases is positively required. I should say more about what 'suspending' actually amounts to.

Suspending an attitude need not mean that it is inappropriate, or even believed to be inappropriate, but rather that one is not sufficiently positively confident that it is appropriate. Thus, the judgment that indignation is inappropriate may be the result of my rational deliberation, but I may feel that my emotions are a surer guide and hence reject the rational deliberation, or believe that I must have made an error somewhere in the deliberation, or believe that the deliberation may be malfunctioning due to high affect. Rejecting the deliberation, or the link between the moral reactive attitudes and the conditions we have discovered through naturalistic examination of the attitudes, amounts to skepticism over their appropriateness, in the face of which skepticism we may feel that suspension of the attitudes is the safer option, preferring the risk of unpunished violations to that of inflicting harms that are undeserved. How we actually do judge between these options is itself a fact about the moral community and not something given to us as a brute fact about our social existence, and may differ across moral communities and evolve within a moral community. The exact content of the moral demands we make of others as members of the moral community and of ourselves as judges (e.g., whether we are rightly fastidious in our efforts to avoid error, or whether this makes too high a demand on us as judges) may change.

This does not necessarily mean that each community has its own conception of moral responsibility, but it does warn us against defining moral responsibility as involving 
substantive moral norms beyond a minimal norm for mutual regard, for this must be presupposed by the very notion of a moral community. Instead, the concept of moral responsibility is better regarded as a functional concept, and the conditions for applying this concept seen functionally as exchanges in moral dialogue.

Typically these exchanges occur at the object level and take for granted the natural facts of our psychology. However, meta-level dialogue is a possibility. Strawson claims that such a dialogue would focus on the potential losses and benefits to human existence and could not make us suspend our reactive attitudes universally or forever. Perhaps he is right about this, but this does not rule out the possibility that our skepticism in regard to some particular case, and our substantive judgment that letting some guilty people go free is a potential loss outweighed by the benefit of not punishing the innocent, could not bring us to and in fact require us to suspend our reactive attitude. Such meta-dialogue could not be required when it is our everyday interpersonal relationships at issue; in fact it might be curiously inappropriate to constantly reassess the rational grounds of the relationships you are in, still less to expect the other party to give you rationalizing explanations for them. But when one is not in such a relationship, but, perhaps, contemplating whether to enter such a relationship, or assessing someone else's relationship, the case is different; Strawson's account fails to notice this, so even if we accept his claim that the participant reactive attitudes do not require justification, this is not so for moral reactive attitudes, no matter how odd or solipsistic-seeming we find the man who is resentful but would not be indignant, or who is indignant but would not be resentful. The examples given here show that this is not necessarily so odd after all.

To be responsible is to be appropriately held responsible, which is for a reactive attitude to be an apt response. But now an unexpected question has arisen: which reactive attitudes? Since one can appropriately be resentful without being indignant, if we say that we are responsible when indignation is an apt response towards us, we will be responsible in fewer cases than if we say that we are responsible when resentment is an apt response towards us. Start of an answer may be that the attitudes of the individual judge (whether this is the injured party or not) is less important than attitudes that can be attributed to the moral community itself; this relies on collectives having a certain amount of autonomy so that it makes sense to say things like this.

Here is an example in the case of belief: a belief that $p$ can be attributed to a collective if belief in some premises can be attributed to the members of the collective, belief in a rule can be attributed to the members of the collective, and it can be shown that $p$ can be 
concluded from those premises and that rule. The members of the collective must accept $p$ even if they do not actually have a belief that $p$; in fact, discursive dilemmas have shown us that they may believe not- $p$. Similarly, if a certain description of an act as violating a particular moral demand is agreed by the members of the moral community as accurate, and it is believed by the members of the moral community that no excusing or exempting condition obtains, and it is believed by the members of the moral community that in such circumstances resentment is appropriate, then we can attribute resentment to the moral community even if no member of the actual moral community experiences resentment. Furthermore, this procedure is enacted in the form of an agonistic dialogue: the accused wins if he could (in principle) show that an excuse or exemption obtains and loses if he cannot. What makes him an apt object of resentment, then, is the fact that he cannot justify himself according to the standards of the moral community, and he can validly be held accountable by the moral community (because he is a member of it) to provide such justifications.

I would not go so far as to say that this actually makes the agent morally responsible, but what I would say instead is that there is an obligation on the part of the community to hold the agent morally responsible, that is to say, to blame him. Like most obligations, this is an obligation that competes with other obligations and will sometimes lose. Perhaps this is what happens when we entertain a skeptical hypothesis; we are just not sure enough to actually blame. However, when we do blame, that blame expresses the resentment attributable to the moral community (as well as the blamer's own, if the blamer is the injured party and does feel resentment). The question of moral responsibility itself is always going to be vulnerable to skepticism and anti-realism; an emphasis instead on first-person responsibility-attributions, that I have argued elsewhere Strawson's account largely seems to be in terms of, or what I would call an obligation to blame, is both more tractable and more relevant to our practical problems. 


\section{Notes:}

${ }^{1}$ David Botting is a post-doctoral researcher at ArgLab, Institute of Philosophy of Language, Universidade Nova de Lisboa, Portugal. Funding for this research was received from Portuguese Foundation for Science and Technology (FCT) under grants SFRH/BPD/77687/2011 and PTDC/FIL-FIL/110117/2009. e-mail: davidbotting33@yahoo.co.uk

2 See Jonathan Bennett, “Accountability,” in M. McKenna and P. Russell (eds.) Free Will and Reactive Attitudes: Perspectives on P.F. Strawson's "Freedom and Resentment” (Surrey, England: Ashgate, 2008).

${ }^{3}$ P.F. Strawson, "Freedom and resentment," in Freedom and resentment and other essays (New York: Routledge, 2008), pp.15-16.

${ }^{4}$ P.F. Strawson, ibid., pp.17-18.

${ }^{5}$ Bennett W. Helm, "Responsibility and dignity: Strawsonian themes," in Carla Bagnoli (ed.) Morality and the emotions (New York: Oxford University Press, 2011), p.223.

${ }^{6}$ Bennett W. Helm, ibid., p.224.

${ }^{7}$ P.F. Strawson, ibid., p.26.

${ }^{8}$ P.F. Strawson, ibid., p.27.

${ }^{9}$ Bruce Waller, Against moral responsibility, (Cambridge, Massachusetts and London, England: The MIT Press, 2011), p.313.

${ }^{10}$ Bruce Waller, ibid., p.313. 


\section{Bibliographical references:}

Jonathan Bennett, “Accountability," in M. McKenna and P. Russell (eds.) Free Will and Reactive Attitudes: Perspectives on P.F. Strawson's "Freedom and Resentment" (Surrey, England: Ashgate, 2008).

P.F. Strawson, "Freedom and resentment," in Freedom and resentment and other essays (New York: Routledge, 2008).

Bennett W. Helm, "Responsibility and dignity: Strawsonian themes," in Carla Bagnoli (ed.) Morality and the emotions (New York: Oxford University Press, 2011).

Bruce Waller, Against moral responsibility, (Cambridge, Massachusetts and London, England: The MIT Press, 2011). 